\title{
Field survey around strong motion stations and its implications on the seismic intensity in the Lushan earthquake on April 20, 2013
}

\author{
Yefei Ren $\cdot$ Kun Ji $\cdot$ Ruizhi Wen $\cdot$ Xutao Huang
}

Received: 23 September 2013/Accepted: 1 December 2013/Published online: 8 January 2014

(C) The Seismological Society of China, Institute of Geophysics, China Earthquake Administration and Springer-Verlag Berlin Heidelberg 2014

\begin{abstract}
The $M_{\mathrm{s}} 7.0$ Lushan earthquake on April 20, 2013 is another destructive event in China since the $M_{\mathrm{s}} 8.0$ Wenchuan earthquake in 2008 and $M_{\mathrm{s}} 7.1$ Yushu earthquake in 2010. A large number of strong motion recordings were accumulated by the National Strong Motion Observation Network System of China. The maximum peak ground acceleration (PGA) at Station 51BXD in Baoxing Country is recorded as $-1,005.3 \mathrm{~cm} / \mathrm{s}^{2}$, which is even larger than the maximum one in the Wenchuan earthquake. A field survey around three typical strong motion stations confirms that the earthquake damage is consistent with the issued map of macroseismic intensity. For the oscillation period 0.3-1.0 $\mathrm{s}$ which is the common natural period range of the Chinese civil building, a comparison shows that the observed response spectrums are considerably smaller than the designed values in the Chinese code and this could be one of the reasons that the macroseismic intensity is lower than what we expected despite the high amplitude of PGAs. The Housner spectral intensities from 16 stations are also basically correlated with their macroseismic intensities, and the empirical distribution of spectral intensities from Lushan and Wenchuan Earthquakes under the Chinese scale is almost identical with those under the European scale.
\end{abstract}

Keywords Lushan earthquake $\cdot$ Strong motion recording · Macroseismic intensity · Field survey · Earthquake damage $\cdot$ Spectral intensity

Y. Ren $\cdot$ K. Ji $\cdot$ R. Wen $(\bowtie) \cdot$ X. Huang

Key Laboratory of Earthquake Engineering and Engineering Vibration, Institute of Engineering Mechanics, China Earthquake Administration, Harbin 150080, China

e-mail: ruizhi@iem.ac.cn

\section{Introduction}

At 8:02, April 20, 2013, a destructive earthquake occurred in Lushan Country, Sichuan Province. The magnitude is $M_{\mathrm{s}} 7.0$ and hypocenter depth is $13 \mathrm{~km}$. Up to April 26, 2013, the earthquake had caused 196 dead, 21 missing, and 11,470 injured. It is another destructive shallow earthquake since $M_{\mathrm{s}} 8.0$ Wenchuan earthquake in 2008 and $M_{\mathrm{s}} 7.1$ Yushu earthquake in 2010 in China mainland.

During the main shock, a large number of strong motion recordings were accumulated by the National Strong Motion Observation Network System of China, and the maximum peak ground acceleration (PGA) of $-1,005.3 \mathrm{~cm} / \mathrm{s}^{2}$ was obtained in the station coded 51BXD in Baoxing Country (Wen et al. 2013a). The PGA between 708 and $1,414 \mathrm{~cm} / \mathrm{s}^{2}$ is one of the criteria to define the macro intensity $X$ in Chinese national code "Chinese seismic intensity scale" (IEM and IGP, CEA 2008). However, the seismic intensity in Baoxing Country is in fact assessed as VII by the post-earthquake investigation. In some other near-field strong motion stations, large PGAs were also observed, such as the stations coded 51BXZ and 51YAD, that are 583.2, 316.4, $-387.2 \mathrm{~cm} / \mathrm{s}^{2}$ and -524.4 , $398.6,196.3 \mathrm{~cm} / \mathrm{s}^{2}$ in the East-West (EW), North-South (NS), and Up-Down (UD) components, respectively (Wen et al. 2013b). Also both are located in the area of seismic intensity VII. The amplitude of the observed PGAs seems higher but the macroseismic intensity is a little bit lower. It is better to check the running status of the instruments of these stations during the earthquake.

Of course, the ground motion parameters are not the only metrics for measuring the intensity of an earthquake which quantifies the effects of the earthquake on the Earth's surface, human beings, objects of nature, and manmade structures. The strong motion observation network 
could immediately process the observational data and quickly announce the instrumental intensity map, such as JMA intensity and ShakeMap intensity. There is a need for analyzing the strong motion parameters associated to the macroseismic and instrumental seismic intensity, and the Lushan earthquake provides a chance.

In this paper, we investigate the earthquake damage on buildings around three typical strong motion stations in the Lushan earthquake and manage to find the correlation between the strong ground motion and building damage. Then the observed response spectrum is compared with the design spectrum to find the implications on the building damage as well. The spectral intensity is calculated and compared with the macro intensity to evaluate the correlation between them.

\section{Macroseismic and instrumental seismic intensity}

Figure 1 shows the isoseismals map released by China Earthquake Administration (CEA) and the distributed nearfield strong motion stations which obtained the recordings in the Lushan earthquake. The maximum intensity is IX covering the Lushan Country and the long axis of isoseismal lines has the northeast-southwest orientation. The total area above intensity VI is $18,682 \mathrm{~km}^{2}$. The rectangle shown in Fig. 1 is the surface projection of the fault rupture

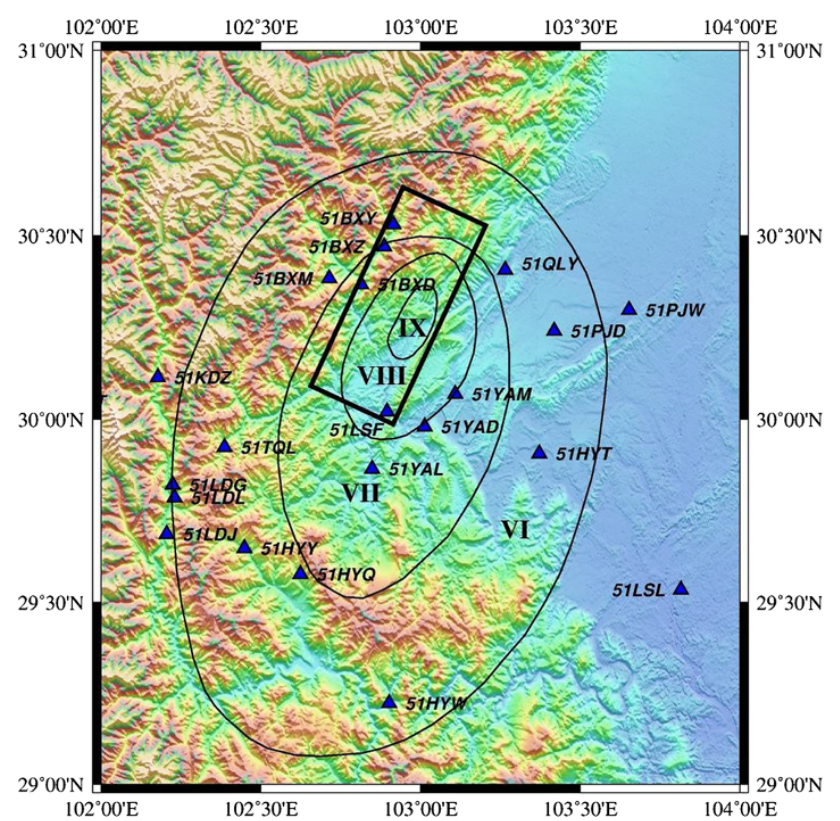

Fig. 1 The isoseismals and near-field strong motion stations of the Lushan earthquake. The rectangle represents the surface projection of the fault rupture plane estimated by Wang et al. (2013). The station codes are labeled. There is no station located in the area of seismic intensity IX. The station 51BXD which obtained the maximum PGA of $-1,005.3 \mathrm{~cm} / \mathrm{s}^{2}$ is located in the area of seismic intensity VII plane estimated by Wang et al. (2013) using the finite fault inversion method, which covers all regions of intensity IX and most part of intensity VIII. Within 3 days followed the main shock, about 3,000 aftershocks occurred in an area of $45 \times 20 \mathrm{~km}^{2}$ located in the Baoxing, Qionglai, Lushan, and Tianquan Countries (Liu et al. 2013), which is consistent with the above-mentioned fault rupture plane given by Wang et al. (2013).

It is well known that a large area of surface rupture is found in the Wenchuan earthquake where the seismic intensity is assessed as X or XI. However, the evidence of the surface rupture in the Lushan earthquake has not been found, maybe that is one of the reasons why the earthquake damage is not as heavy as in the Wenchuan earthquake. It is fortunate that there are some strong motion stations located in the meizoseismal area in the main shock as shown in Fig. 1. Therefore, it becomes possible that these recordings and the field survey of the strong motion stations can give some implications on the seismic intensity.

For 16 stations located within the intensity VI in Fig. 1, the instrumental seismic intensity, defined as $I_{\mathrm{I}}$, is calculated by the method proposed by Wald et al. (1999) which depends on the ground motion parameter of PGA for the low intensity and peak ground velocity (PGV) for the high intensity, respectively. The method has been practiced in the "ShakeMap" system in the USA. Figure 2 shows the calculated result and its comparison with the surveyed macroseismic intensity, defined as $I_{\mathrm{M}}$. It is satisfactory that the $I_{\mathrm{I}}$ for the stations 51BXD and 51BXZ which have the large PGAs are both consistent with the macroseismic

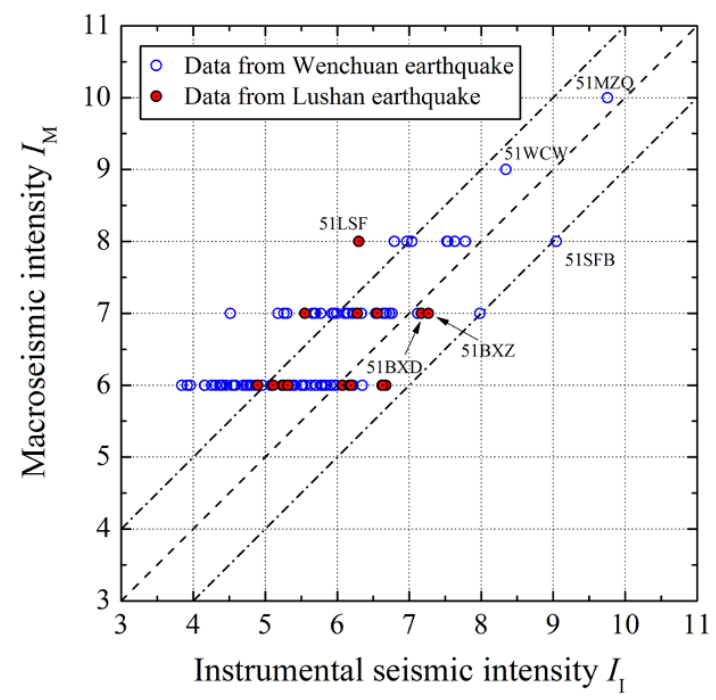

Fig. 2 The comparison of macroseismic and instrument seismic intensities in the Lushan earthquake and the Wenchuan earthquake. Dashed and dotted lines mean the variety of \pm 1 unit of intensity. Hereby for keeping uniform with the spectral intensity, the Arabic numerals are indicated for the macroseismic intensity instead of the Roman numerals 
intensity, defined as $I_{\mathrm{M}}$, but the maximum $I_{\mathrm{M}}=$ VIII at the station 51LSF is highly different with the $I_{\mathrm{I}}$. Furthermore, the $I_{\mathrm{I}}$ for the stations in the Wenchuan earthquake is also calculated as shown in Fig. 2. There are eight stations of which the $I_{\mathrm{I}}$ is larger than the maximum in the Lushan earthquake, which means that the PGVs are also larger because the high $I_{\mathrm{I}}$ is predominantly dependent on PGV. Figure 2 also shows that the $I_{M}$ mostly corresponds to the range of $I_{\mathrm{I}} \pm 1$ unit of intensity, except the $I_{\mathrm{M}}=\mathrm{VI}$ in the Wenchuan earthquake which corresponds to the wide variation from 4 to 7 of $I_{\mathrm{I}}$.

\section{Ground motion and field survey of strong motion stations}

Under the support of the scientific investigation project of the China Earthquake Administration (CEA), we surveyed the earthquake damage of the nearby buildings around the stations 51BXD, 51LSF, and 51YAD. All these three stations obtained the recordings in the main shock. Some parameters are listed in Table 1, including the site condition, epicenter distance, rupture distance, PGA, and PGV.

\subsection{Station 51BXD}

The station 51BXD is located beside the Baoxing Earthquake Disaster Mitigation Board Office where the elevation is $1,022 \mathrm{~m}$. It is also located on a steep hillside which is in the center of the first terrace of the left bank of Dong River, $35 \mathrm{~m}$ from the leading edge. There is a $\mathrm{V}$-shaped valley landscape around the station in terms of a 1,500 m-elevation mountain and $300 \mathrm{~m}$-width valley. The accelerometers are installed on the granite outcrop site, $12 \mathrm{~m}$ above the flat terrace.

The observed PGAs and PGVs of 51BXD are $-1,005.3$, $823.6,478.1 \mathrm{~cm} / \mathrm{s}^{2}$ and $24.5,24.2,11.7 \mathrm{~cm} / \mathrm{s}$ in the $\mathrm{EW}$, NS, and UD components, respectively, as shown in Fig. 3. It is the first strong motion recording with more than $1 \mathrm{~g}$ PGA obtained at free field site in China, thus it is a milestone event in strong motion observation history of China (Wen et al. 2013a). However, it should be noticed that the PGVs are not simultaneously as a large level as the PGAs.

The observed acceleration response spectrum of each horizontal component is compared with the predicted values calculated by Huo (1989), as shown in Fig. 4. It represents that the observed values at short-period part (below $0.2 \mathrm{~s}$ ) are remarkably larger than the predicted values, and at long-period part (above $0.5 \mathrm{~s}$ ) are remarkably smaller. It is possible that the fault rupture releases a majority of highfrequency energy since the rupture lasted only about $10 \mathrm{~s}$ (Wang et al. 2013).

Furthermore, the observed horizontal acceleration response spectrum is also compared with the design spectrum stipulated by the "Code for seismic design of building (GB 50011-2010)" of China (MOHURD 2010), as shown

Table 1 The ground motion parameters of three surveyed stations

\begin{tabular}{|c|c|c|c|c|c|c|c|c|c|}
\hline \multirow[t]{2}{*}{ Station code } & \multirow[t]{2}{*}{ Site condition } & \multirow[t]{2}{*}{ Epicentral distance $(\mathrm{km})$} & \multirow[t]{2}{*}{ Rupture distance $(\mathrm{km})$} & \multicolumn{3}{|c|}{ PGA $\left(\mathrm{cm} / \mathrm{s}^{2}\right)$} & \multicolumn{3}{|c|}{$\mathrm{PGV}(\mathrm{cm} / \mathrm{s})$} \\
\hline & & & & EW & NS & UD & EW & NS & UD \\
\hline 51BXD & Rock & 9.7 & 16.6 & $-1,005.3$ & 823.6 & 478.1 & 24.5 & 24.2 & 11.7 \\
\hline $51 \mathrm{LSF}$ & Soil & 31.9 & 4.1 & 387.4 & 357.0 & -267.4 & 13.8 & -13.0 & 13.7 \\
\hline 51YAD & Soil & 38.4 & 9.4 & -524.4 & 398.6 & 196.3 & 13.6 & -16.3 & 7.0 \\
\hline
\end{tabular}
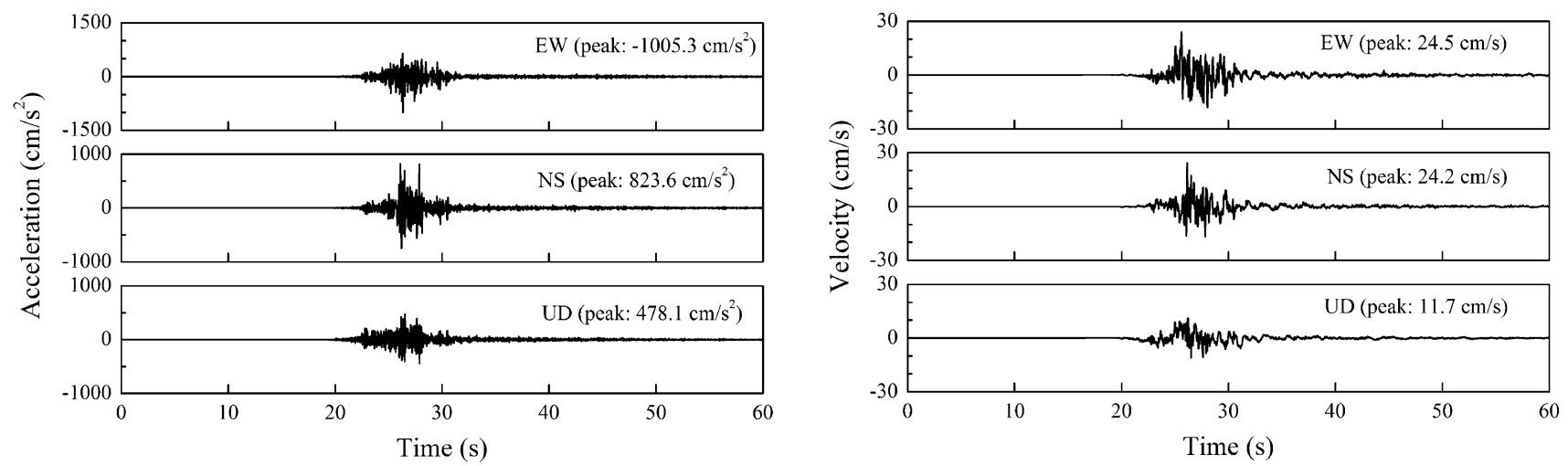

Fig. 3 Acceleration and velocity time-histories observed in the Lushan earthquake for the station 51BXD 


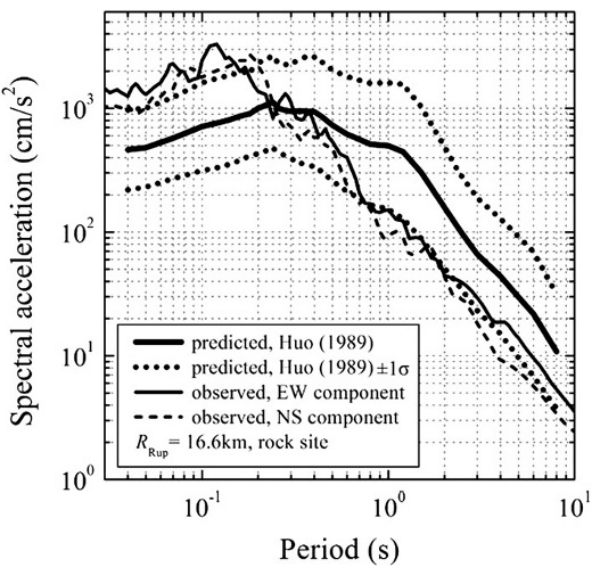

Fig. 4 Comparison of the observed and predicted acceleration response spectrums for the station 51BXD. The predicted values are calculated by Huo (1989) which is commonly used in China

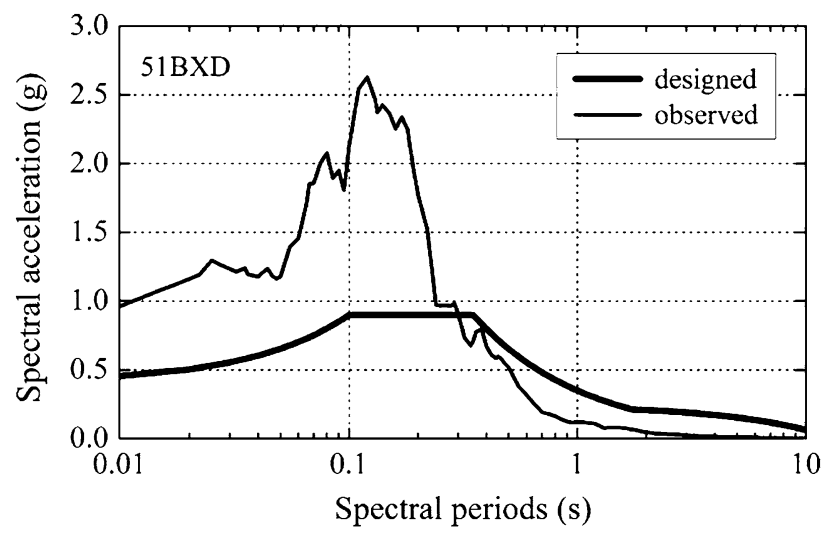

Fig. 5 Comparison of the observed acceleration response spectrum and the designed spectrum for the station 51BXD. The designed spectrum is calculated under the case of rare earthquake

in Fig. 5. The observed spectrum is vectorially synthesized by two orthogonal horizontal components. The design spectrum is considered under the case of rare earthquake. In Fig. 5, the observed values are remarkably larger than the designed values when the spectral period is smaller than $0.3 \mathrm{~s}$. However, for the oscillation period from 0.3 to $1.0 \mathrm{~s}$, which is the natural period range of the common civil buildings in China, the observed values are smaller than the designed values; that is, indicating that those seismicdesigned civil buildings in Baoxing Country could not suffer from the Lushan earthquake.

In addition, at the long-period part $(>1 \mathrm{~s})$ the observed spectrum is much smaller than the design spectrum. Thus, the structures with the long natural period, such as the dams, long-span bridges, power-transmission towers and other lifeline facilities, large gymnasiums, and high-rise buildings cannot be heavily damaged while being suffered from this recording.

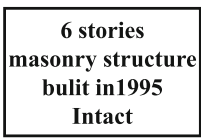

(1)

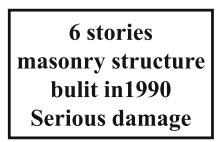

(2)

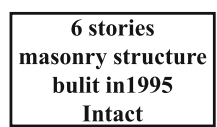

(3)
(4)
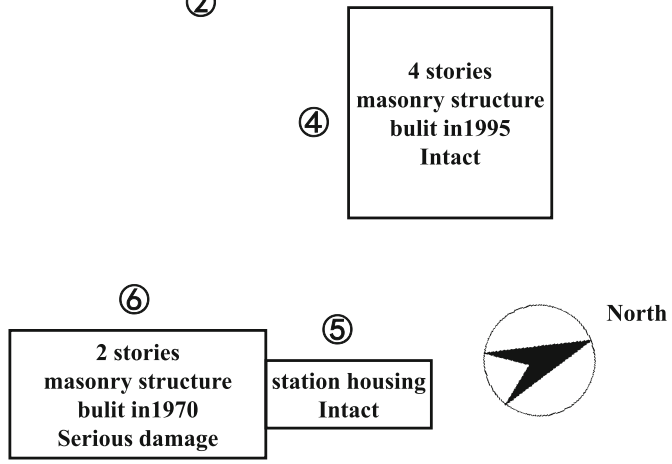

Fig. 6 Schematic view of the plane location of six surveyed buildings around the station 51BXD and their structure type, construction year, number of story, and damage description

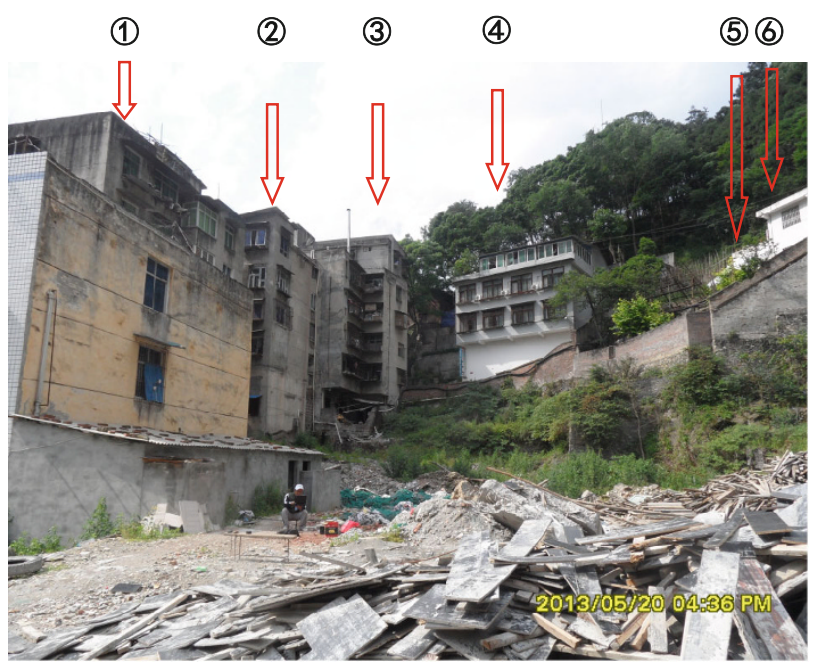

Fig. 7 Spatial locations of the six surveyed buildings around the station 51BXD

Figure 6 shows a schematic view of the plane location, structure type, construction year, number of story, and damage description of six surveyed buildings around the station 51BXD and Fig. 7 shows their spatial locations. There are three six-story masonry structures (Nos. (1), (2), and (3) and one four-story masonry structure (No. (4) built in 1990s among which the three ones are intact, and the other one is seriously damaged. A two-story masonry structure of the Baoxing Earthquake Disaster Mitigation Board Office (No. (6)), which is located just beside the housing of the station, has the serious damage. However, the housing of the station is intact. There is a possibility that the building of No. (6) is not constructed under the specification of the design code since it was built in 1970 . Figure 8 indicates that the instruments of 51BXD are 

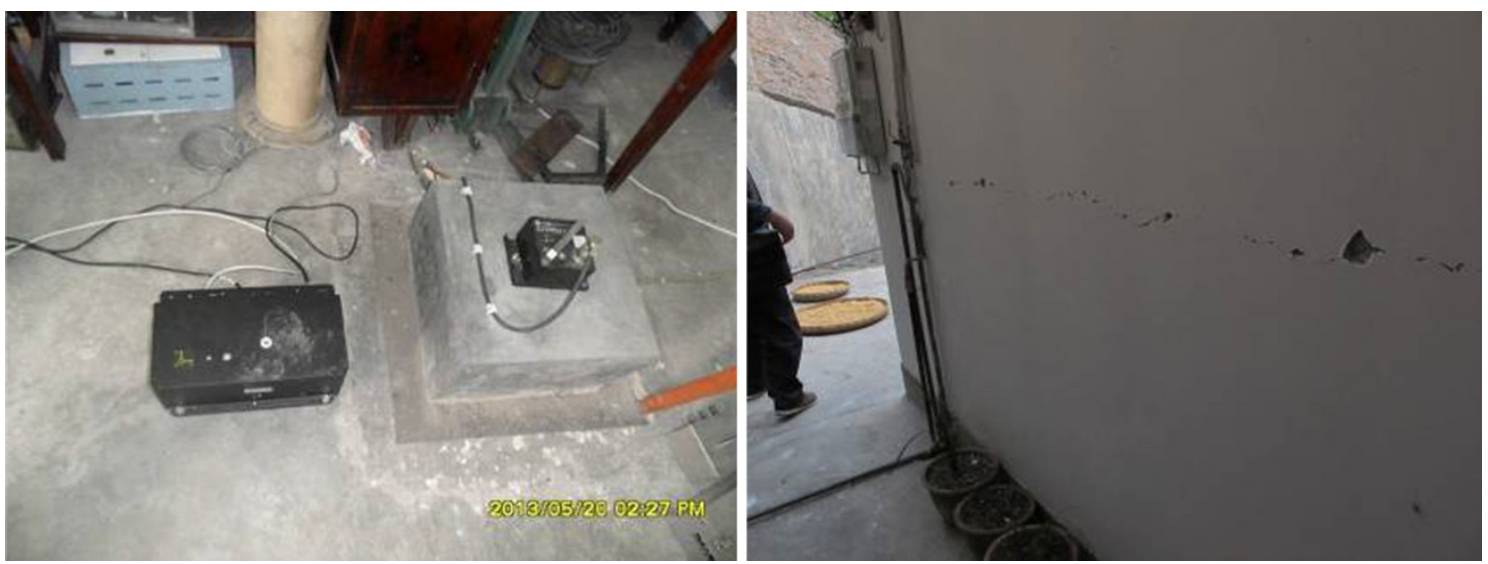

Fig. 8 Two cases of the field survey results for the station 51BXD. The left picture indicates that the instruments of 51BXD are running correctly. The right picture shows a horizontal crack penetrating the gable wall of the No. (5) building
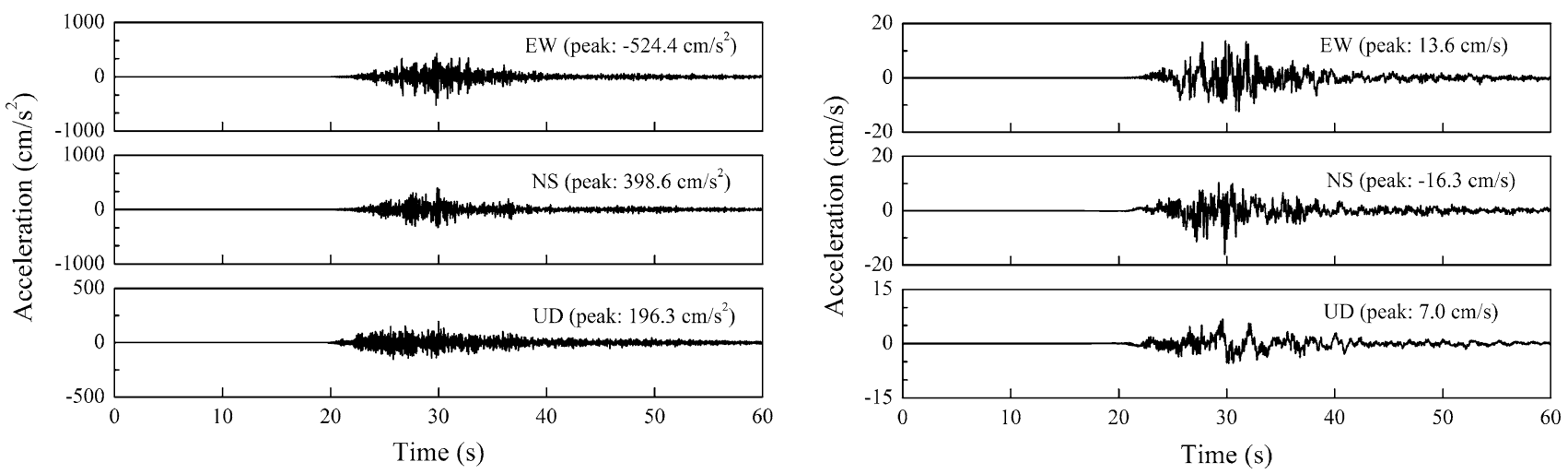

Fig. 9 Acceleration and velocity time-histories observed in the Lushan earthquake for the station 51YAD

running correctly and shows a horizontal crack that penetrates the gable wall of the No. (5) building. The gable wall bears the load of above structure so that the penetrating crack makes the building nonfunctional.

The above-described survey results show that the macroseismic intensity is appropriate as VII around the station 51BXD.

\subsection{Station 51YAD}

The 51YAD station is located in Ya'an city where the elevation is $595 \mathrm{~m}$. The station is also located in the trailing edge of the second terrace of the right bank of Qingyi River, $300 \mathrm{~m}$ away from the leading edge. The terrain is flat and its average uppermost- $20 \mathrm{~m}$ shear wave velocity $V_{\mathrm{s} 20}$ is $190 \mathrm{~m} / \mathrm{s}$, classified as the soft soil site.

Its observed PGAs and PGVs are -524.4, 398.6, $196.3 \mathrm{~cm} / \mathrm{s}^{2}$ and $13.6,-16.3,7.0 \mathrm{~cm} / \mathrm{s}$ in the EW, NS, and UD components, respectively, as shown in Fig. 9. As same as the station 51BXD, the PGVs of 51YAD are also not as a large level as the PGAs. It is also found that the observed

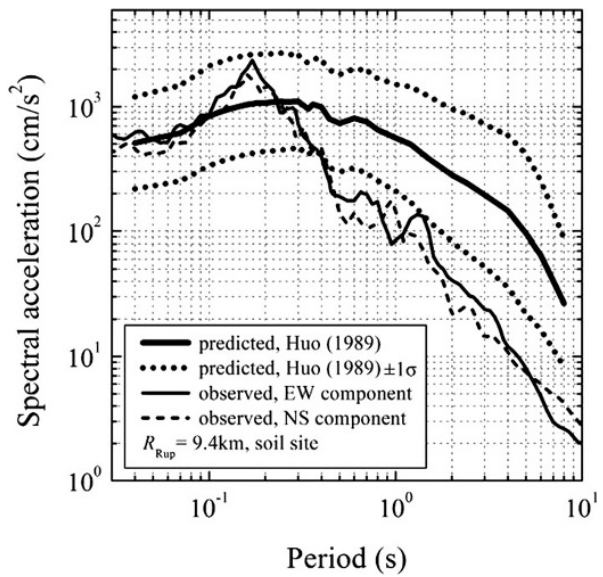

Fig. 10 Comparison of the observed and predicted acceleration response spectrums for the station 51YAD. The predicted values are calculated by Huo (1989) which is commonly used in China

horizontal acceleration response spectrum at long-period part (above $0.5 \mathrm{~s}$ ) is remarkably smaller than the predicted value calculated by Huo (1989), as shown in Fig. 10. The 
short-period parts (below $0.2 \mathrm{~s}$ ) of the observed values are kept in the range of the mean predicted values plus or minus one standard deviation. The comparison between the observed and designed horizontal response spectrum for the station 51YAD has the same results as the station

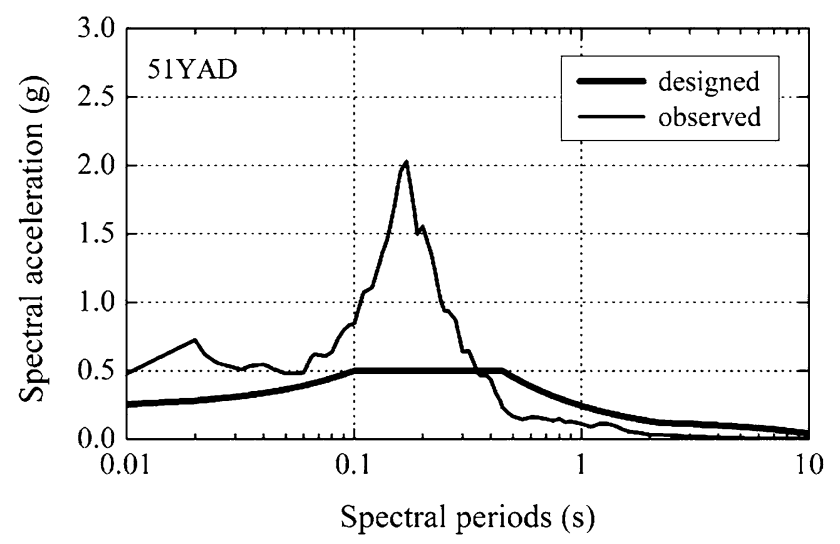

Fig. 11 Comparison of the observed acceleration response spectrum and the designed spectrum for the station 51YAD. The designed spectrum is calculated under the case of rare earthquake

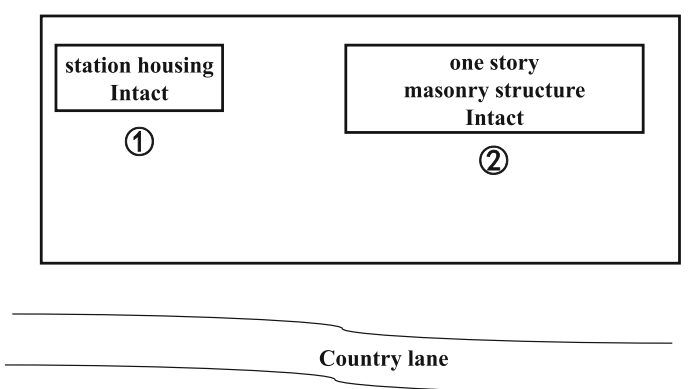

\section{(3)}

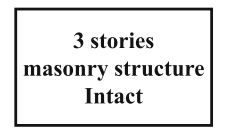

\section{(4)}

\begin{tabular}{|c|}
\hline 3 stories \\
masonry structure \\
Intact
\end{tabular}

Fig. 12 Schematic view of the plane location of four surveyed buildings around the station 51YAD and their structure type, number of story, and damage description
51BXD that deduces the same conclusions, as shown in Fig. 11.

Figure 12 shows a schematic view of the plane location, structure type, number of story, and damage description of four surveyed buildings around the station 51YAD. No. (1) is the station housing which is located on the flat site. It was not damaged in the earthquake and its instruments are running correctly. Also no damage is found on the masonry buildings of Nos. (2), (3), and (4). Figure 13 shows their exterior view and the interior view of the station housing.

\subsection{Station 51LSF}

The 51LSF station is located in the Feixian Town of Lushan Country where the elevation is $643 \mathrm{~m}$. The station is also located on the second terrace of the right bank of Baoxing River, $20 \mathrm{~m}$ away from the leading edge. The average uppermost-20 m shear wave velocity $V_{\mathrm{s} 20}$ of the observed site is $242 \mathrm{~m} / \mathrm{s}$, and the thickness of overlying soil is $6.90 \mathrm{~m}$, classified as the soft soil site.

Its observed PGAs and PGVs are 387.4, 357.0, $-267.4 \mathrm{~cm} / \mathrm{s}^{2}$ and $13.8,-13.0,13.7 \mathrm{~cm} / \mathrm{s}$ in the EW, NS, and UD components, respectively, as shown in Fig. 14. As same as both the stations 51BXD and 51YAD, the PGVs are also not very large. Like the station 51YAD whose observed horizontal acceleration response spectrum at long-period part (above $0.5 \mathrm{~s}$ ) is remarkably smaller than the predicted value calculated by Huo (1989), and the short-period parts (below $0.2 \mathrm{~s}$ ) are within the range of the mean predicted values plus or minus one standard deviation, as shown in Fig. 15.

The comparison between the observed and designed horizontal response spectrum (Fig. 16) shows that at the period below $0.1 \mathrm{~s}$ the observed values are identical as the designed values, at the period between 0.1 and $0.3 \mathrm{~s}$ the observed values are larger than the designed values, and at the period above $0.3 \mathrm{~s}$ the observed values are remarkably smaller than the designed values as same as both the stations 51BXD and 51YAD.
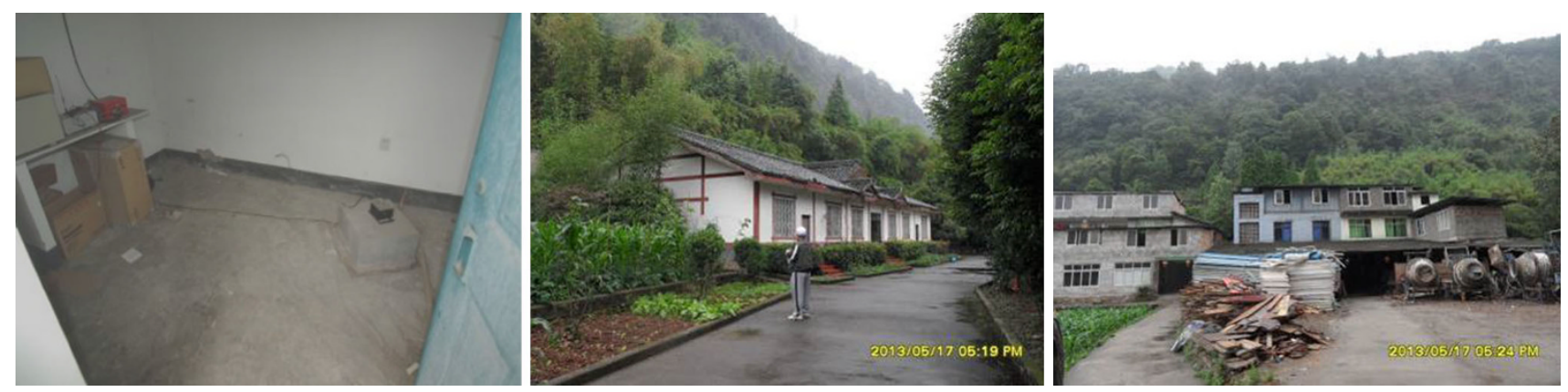

Fig. 13 Photos of the interior view of the station housing (left one), exterior view of the surveyed No. (2) building (middle one) and Nos. (3) and (4) buildings (right one) 

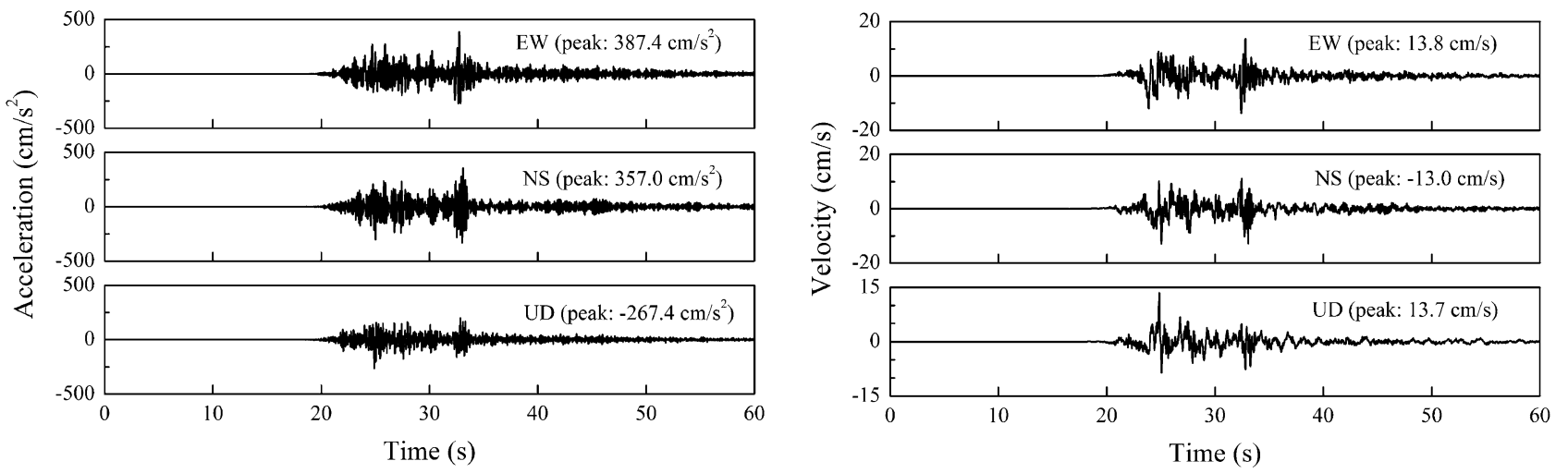

Fig. 14 Acceleration and velocity time-histories observed in the Lushan earthquake for the station 51LSF

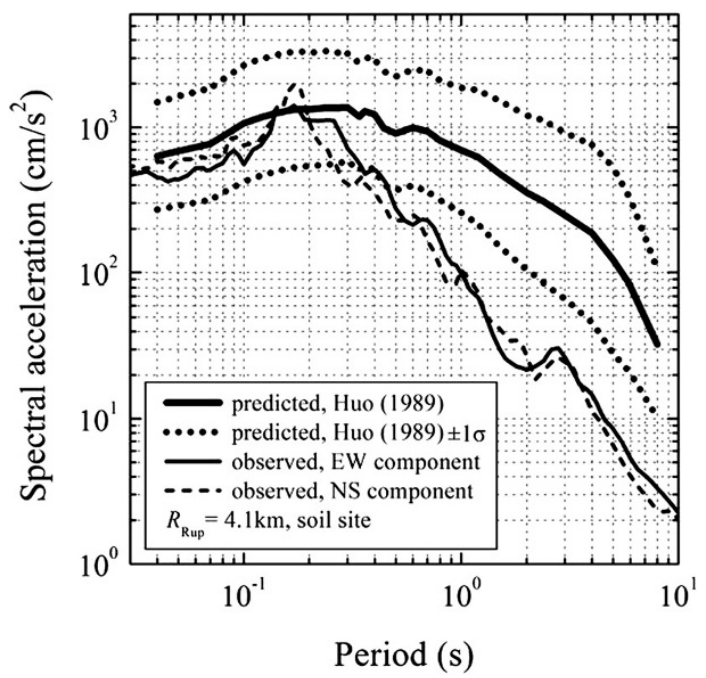

Fig. 15 Comparison of the observed and predicted acceleration response spectrums for the station 51LSF. The predicted values are calculated by Huo (1989) which is commonly used in China

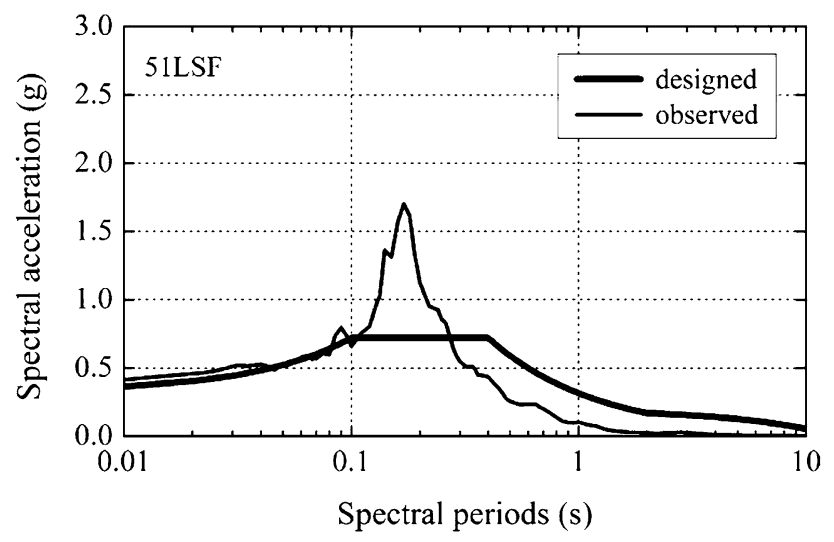

Fig. 16 Comparison of the observed acceleration response spectrum and the designed spectrum for the station 51LSF. The designed spectrum is calculated under the case of rare earthquake

Figure 17 shows a schematic view of the plane location, structure type, number of story, and damage description of four surveyed buildings around the station 51LSF. No. (1) is

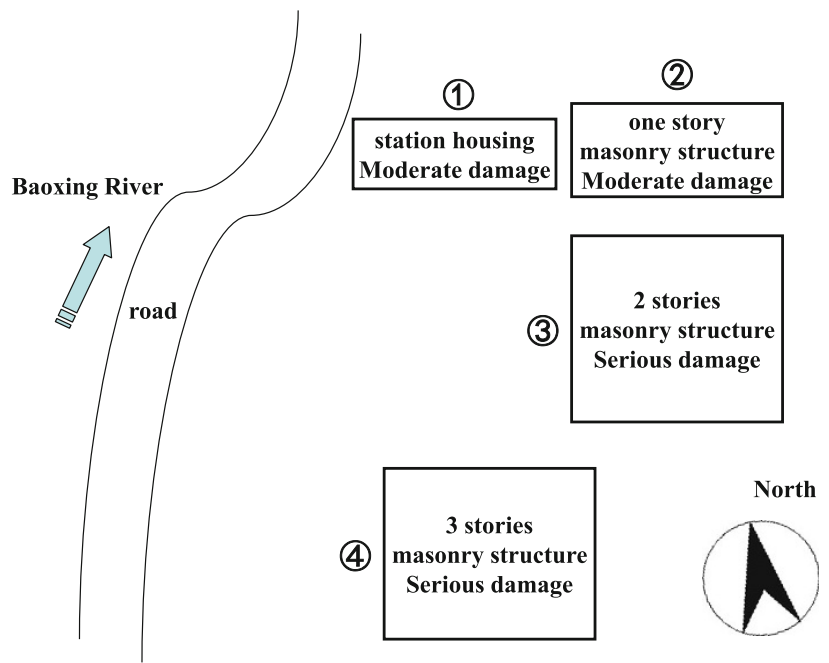

Fig. 17 Schematic view of the plane location of four surveyed buildings around the station 51LSF and their structure type, number of story, and damage description

the station housing which is a masonry structure built in earlier years. The transverse cracks can be found inside and the exterior wall tiles drop out. It is classified as a moderate damage. The instruments are running correctly. The other three buildings are also masonry structures and moderately or seriously damaged. It can be found that the horizontal cracks penetrate the bottom of No. (3) building and the diagonal cracks appear on the corner of the window. Also some horizontal and diagonal cracks can be found inside the No. (4) building in Fig. 18.

According to the above-described survey results, it is clear that the station 51LSF is located inside the area of macroseismic intensity VIII.

\subsection{Discussion}

The above-mentioned survey results show that there is no collapsed building around the strong motion stations 

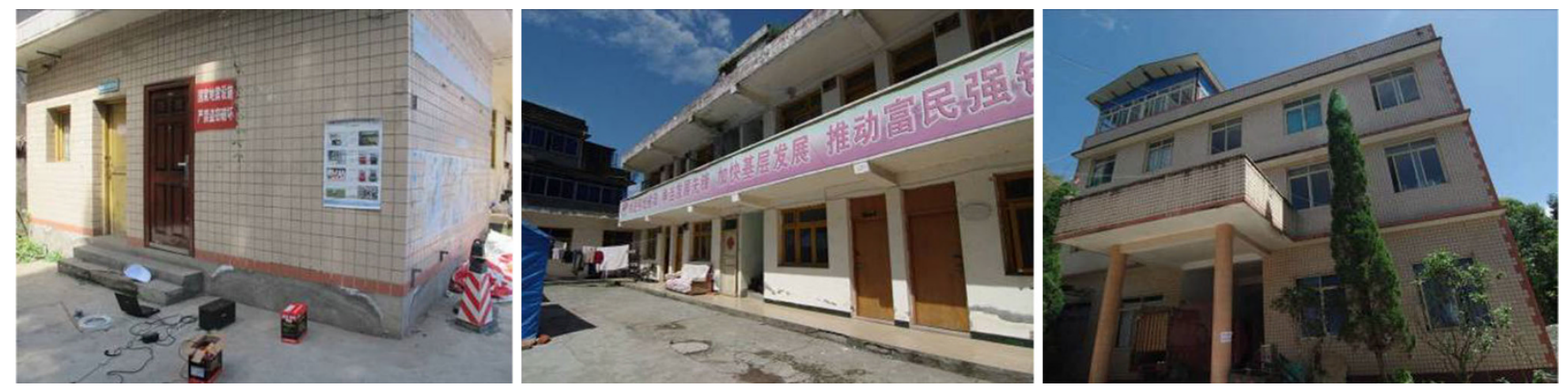

Fig. 18 Photos of the exterior view of the station housing (left one) and surveyed No. (3) (middle one) and No. (4) (right one) buildings

51BXD, 51YAD, and 51LSF, the extent of earthquake damage surrounding the station 51LSF is the most serious, 51BXD is moderate, and 51YAD is slighter. Those are basically consistent with the published map of macroseismic intensity. The analysis of the observed ground motion shows that the high-frequency motion is predominant for each station and the low-frequency motion is remarkably smaller than the empirical predicted values. It is noticed that the station 51BXD is located on a steep hillside; therefore, the observed ground motion will be probably affected by the local site topography. Taking a measurement of ambient vibration along the different elevations of the hillside, Wen et al. (2013a) calculated their H/V spectral ratio and verified the site amplification by the steep slope in the $3-20 \mathrm{~Hz}$ frequency bands.

\section{Comparison of macroseismic and spectral intensities}

The definition of the spectral intensity was initially proposed in 1952 by Housner (1952), known as Housner intensity, and it has been confirmed that the spectral intensity has a good correlation with the earthquake damage. It is represented as follows:

$I_{\mathrm{H}}=\int_{T_{1}}^{T_{2}} S_{\mathrm{v}}(T, \xi) \mathrm{d} T$,

where $I_{\mathrm{H}}$ is the spectral intensity, $S_{\mathrm{v}}$ means the velocity response spectrum, $T$ is the spectral period, $\xi$ is the damping ratio of the single degree of freedom system, usually taking $5 \%$, and $T_{1}$ and $T_{2}$ are the used lower and

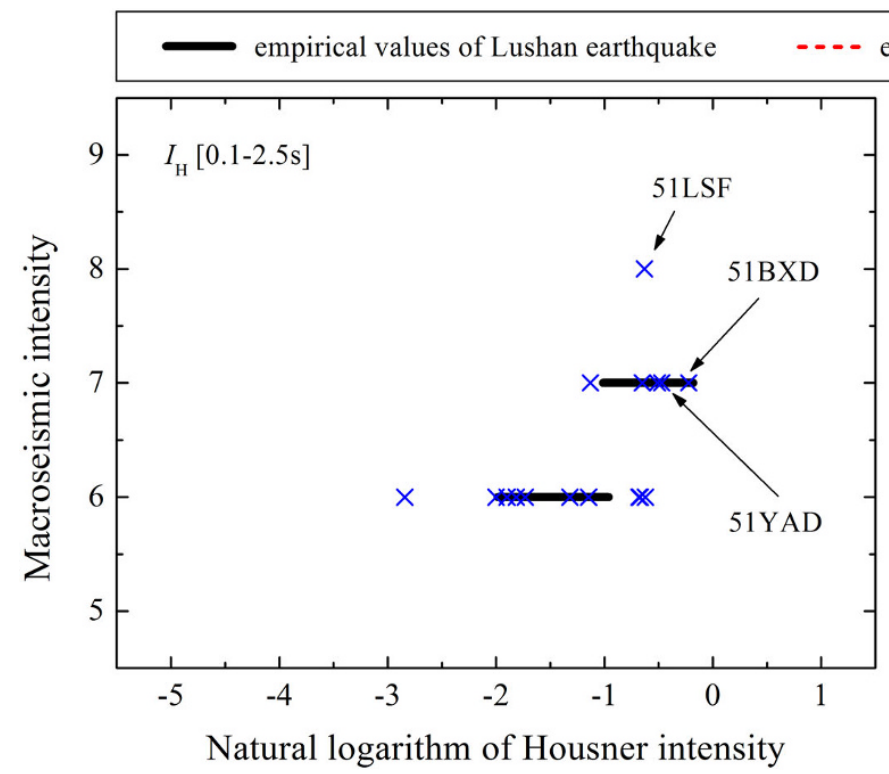

empirical values of EMS

$\times$ observed values in each station

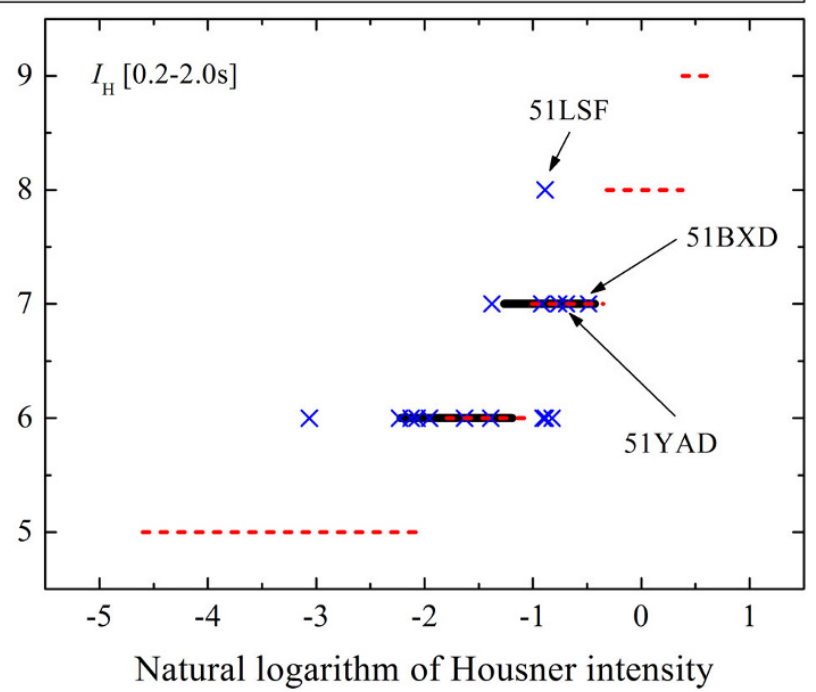

Fig. 19 Relationship of the macroseismic intensity versus Housner spectral intensity $I_{\mathrm{H}}[0.1-2.5 \mathrm{~s}]$ and $I_{\mathrm{H}}[0.2-2.0 \mathrm{~s}]$ calculated in the range of period 0.1-2.5 and 0.2-2.0 s, respectively, for each strong motion station in the Lushan earthquake. For each macroseismic intensity, the $95 \%$ confidence interval of $I_{\mathrm{H}}$ is estimated as their empirical distribution; it is compared with the empirical relationship of the European Macroseismic Scale (EMS) given by Masi et al. (2011). Hereby for keeping uniform with the spectral intensity, the Arabic numerals are indicated for the macroseismic intensity instead of the Roman numerals 
upper limit of the spectral period, generally taking 0.1 and $2.5 \mathrm{~s}$, respectively.

The Housner intensities of 16 stations within the area of macro intensity above VI as shown in Fig. 1 are calculated. The geometric mean of two orthogonal horizontal components is calculated. The computed interval with respect to the spectral period controlled by $T_{1}$ and $T_{2}$ is $0.1-2.5$ and $0.2-2.0 \mathrm{~s}$, as $I_{\mathrm{H}}[0.1-2.5 \mathrm{~s}]$ and $I_{\mathrm{H}}[0.2-2.0 \mathrm{~s}]$, respectively.

Figure 19 shows the calculated results for each station and the $95 \%$ confidence interval is estimated as an empirical distribution range for both grades of macro intensities VI and VII. The Arabic numerals are indicated for the macroseismic intensity instead of the commonly Roman numerals in order to keep it uniform with the spectral intensity. It is represented that: two distributions are well separated which preliminarily yields a verification that the spectral intensity has a good correlation with the macroseismic intensity. The computed empirical distribution in the case of $I_{\mathrm{H}}[0.2-2.0 \mathrm{~s}]$ is compared with the empirical one of the European Macroseismic Scale (EMS) (Grünthal 1998) given by Masi et al. (2011). It is noted that the EMS has the nearly approximate criteria with the Chinese seismic intensity scale (IEM and IGP, CEA 2008) for each grade of macroseismic intensity. The comparison result shown in Fig. 19 represents that the empirical distribution of spectral intensity with respect to the macroseismic intensity under the EMS scale is almost identical to the one under the Chinese scale. In addition, both for the macro intensities VI and VII, the average value of the spectral intensity under the Chinese scale is a little bit smaller than the average value under the EMS.

\section{Conclusions}

A field survey around three strong motion stations coded 51BXD, 51YAD, and 51LSF has been taken immediately after the Lushan earthquake occurred. The characteristics of strong ground motion recorded by these stations are analyzed. The correlation between the macroseismic intensity and spectral intensity are researched. The following conclusions can be drawn:

(1) It has been confirmed that the earthquake damage surrounding the surveyed three stations is consistent with the issued macroseismic intensity, though their recorded PGAs are unexpectedly large. All the instruments of three stations are running correctly.

(2) The comparison of the observed response spectrum and the designed spectrum stipulated by the "Code for seismic design of building (GB 50011-2010)" shows that at the period from 0.3 to $1.0 \mathrm{~s}$, which is the natural period range of the common civil buildings in
China, the observed values are considerably smaller than the designed values. That is probably one of the primary causes why the macroseismic intensity in the Lushan earthquake is not as high as we expected, although high amplitude of PGAs are observed.

(3) The Housner spectral intensities for sixteen stations are calculated and correlated with their macroseismic intensities. The results show that it has a good correlation, and the average distribution range of the Housner spectral intensity is also separated for the different macroseismic intensities. The empirical distribution of spectral intensity with respect to the macro intensity under the Chinese scale is almost identical to that under the European scale.

Acknowledgments This work is supported by Science Foundation of Institute of Engineering Mechanics, CEA under Grant No. 2013C03, National Natural Science Fund Nos. 51308515 and 51278473, and Nonprofit Industry Research Project of CEA under Grant No. 201208014. The authors appreciate Dr. Qi Wenhao, Dr. Chen Longwei, Dr. Shan Zhendong, and Dr. Wang Yunlong from IEM, CEA; and Dr. Lu Tao from Institute of Disaster Prevention, CEA for their help in the work of field survey. Dr. Wang Weimin from Institute of Tibetan Plateau Research Chinese Academy of Sciences is also appreciated for sharing his research result about the inversed focal mechanism of the Lushan earthquake.

\section{References}

Grünthal G (ed) (1998). European Macroseismic Scale 1998 (EMS98). European Seismological Commission, sub commission on Engineering Seismology, working Group Macroseismic Scales. Conseil de l'Europe, Cahiers du Centre Européen de Géodynamique et de Séismologie, Luxembourg, 15, pp 1-99

Housner G (1952) Intensity of ground motion during strong earthquakes. California Institute of Technology, Pasedena, pp 1-60

Huo JR (1989). Study on the attenuation laws of strong earthquake ground motion near the source. PhD Dissertation, Institute of Engineering Mechanics, China Earthquake Administration, Harbin, pp 1-299 (in Chinese with English abstract)

Institute of Engineering Mechanics (IEM) and Institute of Geophysics (IGP), China Earthquake Administration (CEA) (2008). The Chinese seismic intensity scale (GB/T 17742-2008). China Standard Press, Beijing, pp 2-4 (in Chinese)

Liu J, Yi GX, Zhang ZW, Guan ZJ, Ruan X, Long F and Du F (2013) Introduction to the Lushan, Sichuan M7.0 earthquake on 20 April 2013. Chin J Geophys. 56(4): 1404-1407 (in Chinese with English abstract)

Masi A, Chiauzzi L, Braga F, Mucciarelli M, Vona M, Ditommaso R (2011) Peak and integral seismic parameters of L'Aquila 2009 ground motions: observed versus code provision values. Bull Earthq Eng 9(1):139-156

Ministry of Housing and Urban-Rural Development of the People's of China (MOHURD) (2010) Code for seismic design for buildings (GB 50011-2010). China Architecture and Building Press, Beijing, pp 31-35 (in Chinese)

Wald DJ, Quitoriano V, Heaton TH, Kanamori H (1999) Relationships between peak ground acceleration, peak ground velocity, 
and modified Mercalli intensity in California. Earthq Spectra 15(3):557-564

Wang WM, Hao JL, Yao ZX (2013) Preliminary result for rupture process of Apr. 20, 2013 Lushan Earthquake, Sichuan, China. Chin J Geophys 56(4):1412-1417 (in Chinese with English abstract)

Wen RZ, Ren YF, Qi WH, Lu T, Yang ZY, Shan ZD, Wang YL (2013a) Maximum acceleration recording from Lushan earthquake on April 20, 2013. J Southwest Jiaotong Univ 48(5):783-791 (in Chinese with English abstract)

Wen RZ, Ren YF, Huang XT, Lu T, Qi WH (2013b) Strong motion records and their engineering damage implications for Lushan Earthquake on April 20. J Earthq Eng Eng Vib 33(4):1-14 (in Chinese with English abstract) 